\title{
EL PREFECTO DEL PRETORIO: UNA FIGURA DOMINANTE DE LA POLÍTICA ROMANA EN EL SIGLO III (192-284)
}

\author{
Miguel P. Sancho Gómez \\ Universidad Católica San Antonio, Murcia
}

Resumen: El artículo analiza el desarrollo de la figura del Prefecto del Pretorio, que desde sus comienzos fue una de las más importantes dentro de las instituciones de estado romanas, pero que con la llegada de los cambios políticos después de la muerte de Marco Aurelio, aumentó su protagonismo hasta el punto de gozar de más poder en ocasiones que el mismo emperador. La coyuntura inestable y las fuertes prerrogativas de las que gozaba convirtieron a ese alto funcionario, mitad militar y mitad burócrata, en un personaje clave dentro de las intrigas políticas romanas, que desde su posición inigualable fue capaz a menudo de eliminar al emperador mediante una conspiración para ocupar su lugar. La situación se hizo tan grave llegado el siglo IV que Constantino decidió retirarle el mando de tropas y las funciones militares, convirtiendo al Prefecto del Pretorio en un juez supremo y organizador del suministro.

Palabras clave: Prefecto del Pretorio, Cómodo, Leto, Macrino, Caracalla, Gordiano III, Filipo el Árabe, Apro, Numeriano, Diocleciano, Constantino.

Abstract: "The Praetorian Prefect: a Commanding Figure of the Roman Politics in the Third Century (199-284)» analyzes the developing of the Praetorian Prefect character, who was from the beginning one of the most important in the roman state institutions, but with the arrival of the political changes after the death of Marcus Aurelius, enhanced his leading role to the point of sometimes exceeding the power of the emperor himself. The instable circumstances and his strong prerogatives turned that high functionary, half bureaucrat half military, into a key figure inside the roman political intrigues, and from his position he was 
quite often able to eliminate the emperor with a conspiracy, and then take his place. The situation was so serious with the rising of the Fourth Century that the emperor Constantine decided to remove the military functions and the troop leading of the Praetorian Prefects, making them supreme judges and high officials of supply organization.

Keywords: Praetorian Prefect, Commodus, Laetus, Macrinus, Caracalla, Gordian III, Phillip the Arab, Aper, Numerian, Diocretian, Constantine.

$\mathrm{D}$ entro de la historia de las instituciones romanas, uno de los puestos con más importancia y abolengo entre los altos cargos de mando se puede hallar sin duda en la figura del Prefecto del Pretorio. ${ }^{1}$ Dotado de amplios poderes tanto civiles como militares en sus comienzos, su evolución posterior le llevará a convertirse en la segunda pieza más importante dentro de la maquinaria de Estado del Imperio romano; provisto de tal omnipresencia en las diferentes facetas políticas, llegará incluso a hacer peligrar la seguridad y la integridad del propio sistema imperial. Finalmente, remodelado y dotado de una fuerza parcialmente reducida, vemos como el cargo mutará para presentarse por duplicado, ${ }^{2}$ y más tarde, con la llegada del siglo iv, eventualmente multitud de prefecturas se crearon en diversas provincias y «partes» del estado romano, aunque ya por entonces privadas de sus importantísimas prerrogativas militares, que de hecho habían convertido la prefectura en una tentadora y suculenta base de partida para el asalto del mismo poder imperial. ${ }^{3}$ Vamos a tratar exactamente el desarrollo de la institución, tal como fue modelándose desde el final de la dinastía Antonina en el siglo ir hasta la aparición de la

1. Ofrecemos a continuación algunas obras de referencia que tratan sustancialmente este ya de por sí extenso tema: L. BLOCH, Instituciones Romanas, Barcelona, 1930; L. Homo, Las Instituciones Politicas Romanas. De la Ciudad al Estado, en H. Berr (dir.), La Evolución de la Humanidad, México, $1958 ;$ A. Passerini, Le coorti pretorie, Roma, 1969; J. Elul, Historia de las Instituciones en la Antigüedad. Instituciones Griegas, Romanas, Bizantinas y Francas, Madrid, 1970; A. H. M. Jones, The Later Roman Empire 284-602. A Social, Economic and Administrative Survey, London, 1973; M. CHRISTOL et. al. (Eds.), Institutions, société et vie politique dans l'empire romain au IVe siècle ap. J.-C: Actes de la table ronde autour de l'oeuvre d'André Chastagnol, Rome, 1992; P. PorenA, Le origini della prefettura del pretorio tardoantica, Roma, 2003; C. Kelly, Ruling the Later Roman Empire, New York, 2004.

2. La Prefectura del Pretorio doble fue usual durante buena parte del siglo iI y iII; llegamos a encontrar en algunas ocasiones hasta tres Prefectos, y posteriormente aumentó esta cantidad a cinco: en 337, el gobierno del Imperio Romano pasó a ser quíntuple, tras la entrada en vigor del testamento de Constantino I que dejaba en el poder tres Augustos (Constantino II, Constante y Constancio II), un César (Dalmacio) y un «rey» del Ponto, Capadocia y la Armenia romana (Anibaliano). Cf. T. D. BARnes, Constantine and Eusebius, London, 1981, 250-252.

3. Cf. A. Brouwers, «Des préfects du prétoire clarissime anterieures au rêgne de Sévère Alexandre», Latomus 5, 1946, 41-46; L. L. Howe, The Praetorian Prefect from Commodus to Diocletian: A. D. 180 - 305 , Roma, 1966. 
Tetrarquía, y posteriormente trazaremos un breve epílogo basado en las disposiciones de Constantino al respecto. Como podremos comprobar, hasta en cuatro ocasiones desde el 193 hasta el 284, los Prefectos del Pretorio se convertirán en cabezas dirigentes de verdaderas tramas y conspiraciones para alcanzar el poder, utilizando sus muchas atribuciones gubernamentales, su rango y su cercanía al emperador para eliminar a este y ocupar su lugar. ${ }^{4}$ Aunque en primer lugar se pudo ver tal acontecimiento como una medida forzosa y excepcional por la situación crítica del Estado romano, conforme va avanzando el siglo III, el papel de los Prefectos del Pretorio a la hora de realizar algunos de los derrocamientos más importantes de emperadores que, en apariencia, se mantenían en el poder con cierta seguridad, parece fuera de toda duda. ${ }^{5}$ En otros casos en cambio, recibieron cierta ayuda para sus planes o se vieron forzados por el clima de inestabilidad reinante.

Una vez superadas las grandes convulsiones de mitad de siglo, comprobaremos como tanto Diocleciano como Constancio I y su hijo Constantino I, lejos de defenestrar a éstos, honraron e independizaron la figura de los prefectos, siguieron contando con ellos para sus tradicionales misiones y otorgándoles además funciones de máxima importancia, tras una cuidadosa selección de los individuos a los que se otorgaban dichos cargos. Incluso llegarán a reconocer, en la labor eficiente y el trabajo desinteresado y responsable de sus rivales en las guerras civiles, factores útiles y provechosos; lejos de la venganza o la depuración, estarán dispuestos a tomar a su servicio a los miembros de los gobiernos caídos más eficaces, honrados y competentes. ${ }^{6}$ Sin duda el Estado romano necesitaba en ese momento todas las ayudas posibles y los emperadores de la Tetrarquía supieron comprenderlo.

Único de entre los de su clase, el Prefecto del Pretorio fue en principio un verdadero jefe militar italiano, para lo cual estaba al mando de todas las fuerzas armadas estacionadas dentro de la península, junto a las de Roma, incluyendo

4. Cf. B. RANKov \& R. Hook, The Praetorian Guard, London, 1994, 3; P. Southern, The Roman Empire from Severus to Constantine, London, 2001, 256.

5. Tampoco puede negarse la gran importancia de los mismos pretorianos, cuya presencia privilegiada en la capital les convirtió en pieza clave durante los vacíos de poder hasta que las capitales imperiales comenzaron a mudarse a las fronteras, perdiendo Roma su importancia. Cf. L. Bloch, op. Cit., 96-97: «Como se recordará, en los litigios para la posesión del trono fueron los pretorianos los que, como únicos representantes del estamento militar estacionado en la capital, decidian con harta frecuencia el asunto». Para los pretorianos, R. F. Evans, Soldiers of Rome: Praetorians and legionnaries, Washington, 1986.

6. Tal es el distinguido caso de Aristóbulo, que pese a la derrota de su señor, fue mantenido en su puesto. Aurelio víctor $(39,15)$ lo llamó «hombre insigne». Había sido Prefecto del Pretorio de Carino, y si es cierta la noticia ofrecida en las fuentes (véanse nn. 61 y 63), sustituía de hecho a su antecesor, asesinado por el césar. Una vez Diocleciano en el poder, borró la titulación del tercer consulado de Carino, pero en un gesto reconocedor de su integridad y su valía, mantuvo el nombre de Aristóbulo como cónsul posterior del 285 junto a su propio nombre. Cf. R. S. Bagnall, A. Cameron, S. R. Schwartz, K. A. Worp, Consuls of the Later Roman Empire, Atlanta, 1987, 104-105. Posteriormente este personaje mantuvo el distinguido favor de Diocleciano, pues lo vemos como procónsul Africae entre el 290 y el 294 y también como Prefecto de Roma en los años 295-296. Cf. también A. H. M. Jones, J. R. Martindale, J. Morris, The Prosopography of the Later Roman Empire, vol I: 260-395, Cambridge, 1975, 106, «T. Cl. Aurelius Aristobulus». Veremos más adelante como esta situación se repetirá en otras ocasiones. Cf. también la n. 66. 
las dos flotas de guerra en Rávena y Misena. ${ }^{7}$ Además, las diferentes milicias rurales y los stationarii, cuya misión era combatir el bandidaje y las revueltas, se encontraban también a su disposición. ${ }^{8}$ Dentro de sus funciones militares, se incluía la responsabilidad de conseguir un abastecimiento adecuado para el ejército. Como personaje de suma importancia dentro del consejo imperial, además gozaba de amplios poderes judiciales en las causas relativas a Italia, en primera instancia o en apelación; durante el siglo II estos poderes serán engrosados con la importante competencia de la jurisdicción criminal. Al fin y al cabo, en su posición de comandante supremo de las tropas estacionadas en el corazón del Imperio, estaba mucho más capacitado y preparado para ejercer la autoridad satisfactoriamente y de modo efectivo en ese sentido; su antecesor en ese ámbito, el Prefecto de la Ciudad, no tenía a su disposición las armas ni las fuerzas suficientes para tal tarea, poseyendo tan solo las cohortes urbanas bajo su mando directo, de manera que carecía de medios para su función. ${ }^{9}$ Septimio Severo redujo el radio de acción del segundo a cien millas alrededor de la ciudad de Roma, de modo que fuese realizable la cobertura de las áreas rurales adyacentes a la Urbs y los suburbios, para cuyo caso alcanzaban las no muy numerosas fuerzas disponibles. ${ }^{10}$ Además, este emperador reforzó de otro modo el poder del Prefecto del Pretorio sobre los otros prefectos: estacionando la Legión II Pártica en el monte Albano, a las afueras de la ciudad, y disponiéndola bajo su mando directo. Severo contaba seguramente con nombrar Prefectos Pretorianos de su máxima confianza, y esta fuerza adicional con la que los servía iba destinada sin duda a controlar al Senado, donde poseía una nada despreciable cantidad de enemigos que

7. Esto incluía no solo las milicias y otras unidades de guardia, sino también diferentes tropas no italianas acuarteladas allí desde distintas partes del Imperio; parece tradicional que en Italia se estacionasen en todo momento algunas unidades distinguidas, como los Ioviani y Herculiani del siglo iv (Cf. Notitia Dignitatum, Occ. VII 3-4). Se puede observar que, pese a estar alejada de los limes y con un peligro de agresión bárbara relativamente inexistente, la península se encontraba aún poblada por gran cantidad de puestos defensivos guarnicionados y fortificados. Cf. Historia augusta, Los Dos Maximinos 23, 1-5; herodiano vini 5, 3-5. Para la flota de guerra, véase la vieja pero excelente obra de C. G. StarR, The Roman Imperial Navy 31 B. C. - A. D. 324, Oxford, 1960, y también V. Снарот, La flotte de Misène. Son histoire, son recrutement, son régime administratif, París, 1967; H. D. L. Viereck, Die römische Flotte. Classis Romana, Hereford, 1975.

8. Tenemos una noticia de amiano marcelino (xxvil 9, 6) que nos proporciona importante información acerca de éstos cuerpos paramilitares o policiales, que trataban de erradicar el bandidaje y el crimen en las áreas campestres durante el Imperio romano; en Isauria eran llamados diogmitas (del griego diagmós, «cazador»). Véase asimismo, para los stationarii en sí, M. F. Petraccia LuCERnONi, Gli stationarii in età imperiale, Roma, 2001.

9. Cf. H. Freis, Die Cohortes Urbanae, Köln, 1967; F. C. Mench, The Cohortes Urbanae of Imperial Rome: an epigraphic study, Ann Arbor, 1979.

10. Véase O. E. Tellegen-Couperus, A short History of Roman Law, Londres, 1993, 80. Para la importante figura de Severo y sus acciones de gobierno, M. PlatnAuER, The life and reign of the emperor Lucius Septimius Severus, Roma, 1965; A. De Ceuleneer, Essai sur la vie et le règne de Septime Sévère, Roma, 1970. A. Birley, Septimius Severus: the African Emperor, Londres, 1971; A. Gaguet - Gagey, Septime Sévère; Rome, l'Afrique et l'Orient, París, 2000; J. Spielvogel, Septimius Severus, Därmstadt, 2006. 
todavía se encontraban en disposición de alistarse en el ejército y reunir tropas bajo sus mandos. ${ }^{11}$ Transcurría entonces el año 193.

Así, este alto funcionario a partir del final del siglo in fue el instrumento por el cual el emperador, cada vez más alejado de la capital por los sucesos fronterizos y la inestabilidad creciente, ejercía su poder en Italia: autoridad militar, potestad civil, acuñación de moneda, administración del territorio y orden judicial (tanto civil como criminal). ${ }^{12}$ No deben olvidarse tampoco sus importantes prerrogativas y responsabilidades respecto al abastecimiento de víveres. ${ }^{13}$ Fueron los únicos de entre los grandes funcionarios imperiales que conservaron inopinadamente el conjunto de atribuciones civiles junto al poder militar, cuando los tiempos marcaban la senda contraria, y así fue hasta que finalmente Constantino les retiraría las atribuciones militares. Completando así la separación global de poderes, el Prefecto del Pretorio se convertirá en un tipo de juez supremo dentro de sus dominios. Entre los honores y los títulos que estructuraban el organigrama de la compleja burocracia del Bajo Imperio, los Prefectos del Pretorio gozaron de una muy alta distinción, el título de Clarissimi, subiendo posteriormente cuando el escalafón se amplió, al máximo título de Illustri entorno al año 350. Por tanto, fueron siempre muy superiores a los spectabilis creados en tiempos de Valentiniano I, y que integraban una tercera categoría a todos los efectos.

11. AURElio víctor 20, 11-14. En la historia Augusta, (Severo, 13, 2-8) se ofrece una espeluznante lista de los nobles y senadores romanos ejecutados por Severo tras terminar con su rival en Occidente, Clodio Albino, por apoyar económicamente o incluso con las armas al que fue brevemente césar de Occidente. Se observa claramente que contaba con un gran número de «enemigos», que a buen seguro aumentarían tras esa cruenta represión. Véase también EUTROPIO VIII 18, DIÓN CASIO LXXVI 7, 3-4 y OROSIO VII 17, 2. No obstante, en algunas ocasiones se ha dudado de la autenticidad de tal noticia. Cf. F. JACQUES, «Les nobiles éxécutes par Septime Sévère selon l’Histoire Auguste: liste de proscription ou énumération fantaisiste?», Latomus 51 (1), 1992, 119-144. Después del famoso edicto de Galieno (año 261), los senadores serán privados del mando militar, y la disposición represiva de Severo con el Senado no podrá volver a repetirse. Cf. Aurelio víctor, 33-34.

12. Cf. G. Mousourakis, A Legal History of Rome. London, 2007, 144.

13. No obstante, en Roma era el Prefecto de la Ciudad quien debía velar casi constantemente por la llegada de alimentos, pues la escasez de cereales, pero sobre todo la de carne y vino, podían dar origen a espantosas revueltas. Cf. Amiano marCelino xiv 6, 1, xV 7, 3-5, xxvil 3, 4; símaco, Informes 9, 7; 35,$1 ; 37,2$. Como el grano egipcio era destinado usualmente a Constantinopla, Roma debía esperar a los cargamentos procedentes de Hispania o África (para este tema, de vital importancia en la política y estrategia imperial, G. RickMAN, The Corn Suply of Ancient Rome, Oxford, 1980); la dependencia italiana en cuanto al avituallamiento de aceite y trigo era tan acusada, que llegaban a establecerse disputas entre pueblos vecinos por la asignación imperial de grano (Cf. Símaco, Informes 18). Véase también símaco Cartas II 7: En los años 383 a 385 la escasez fue tan grave que se tuvo que decretar la expulsión de los extranjeros, medida que afectó al historiador Amiano (véase para este historiador, R. C. Blockley, Ammianus Marcellinus: a study of his historiography and political thought, Brussels, 1975). Símaco solía achacar los acuciantes problemas agrícolas de su tiempo al castigo de los dioses, que desaprobaban la actitud de los emperadores cristianos. Un estudio de la mentalidad política y religiosa del personaje en R. KLEIN, Symmachus: eine tragische Gestalt des ausgehenden Heidentums, Darmstadt, 1971; R. H. BARrow, Prefect and Emperor: the «Relationes» of Symmachus, A.D. 384, Oxford, 1973 (es una traducción anotada con introducción de los Informes); C. Sogno, Q. Aurelius Symmachus: a political biography, Michigan, 2006. Un estudio de la producción agrícola durante el Imperio Tardío en T. Hew IT, Agricultural production in the Roman economy A.D. 200-400, Oxford, 1991. 


\section{Leto y Cómodo, LA Última NOCHE DEL AÑo 192}

Se puede rastrear fácilmente en las fuentes la situación insostenible a la que había llegado la monarquía de Cómodo, hijo y sucesor de Marco Aurelio, durante los últimos años del siglo II. $^{14}$ Puede decirse que la característica principal del reinado, desde el punto de vista administrativo, fue la continua sucesión de altos funcionarios en el cargo de Prefecto del Pretorio, que para añadir todavía más confusión, se halló frecuentemente duplicado por el emperador. Tarruntenio Paterno, personaje muy experto y ya veterano, de la confianza del anterior monarca, ejercía el cargo de Prefecto del Pretorio al comenzar el reinado, pero solo pudo conservarlo dos años (180-182), al verse condenado a muerte como consecuencia de la «conjura de Lucila», desastroso episodio político en el que la ambición sin sentido de la hermana de Cómodo le llevó a tramar un necio complot, que al fracasar desató una brutal represión del emperador; desde ese momento, los antiguos y venerables consejeros colocados junto al joven augusto por su padre comenzaron a ser alejados de los puestos de influencia o directamente asesinados, y Cómodo renovó casi completamente su equipo de gobierno, en el que ya no confiaba por culpa de ese intento de asesinato, forjado en el mismísimo seno de la familia imperial Antonina. ${ }^{15}$ Se puede decir que desde tal momento la práctica totalidad de sus parientes se encontraron bajo sospecha. Lejos de tratarse de un suceso sin importancia, la trama hubo de tener importantes ramificaciones, a juzgar por la calidad de los ejecutados y la cantidad de personalidades políticas que acudieron a esconderse y desaparecieron de escena entonces, entre ellos tres futuros emperadores como Severo, Juliano y Pértinax..$^{16}$ Pero sin duda, el círculo íntimo de consejeros pertenecientes a los hombres de Marco Aurelio fue castigado de forma desproporcionada e injusta, perdiendo posesiones, fortuna y a menudo sus vidas por la ceguera política y el insufrible orgullo de otros. Así, Salvio Juliano, cónsul en el 148 y Prefecto de África en el 169, hubiese tenido como ocasión única e inmejorable, si hubiese deseado verdaderamente conspirar contra Cómodo, el mismo momento del fallecimiento de Marco, pues se encontraba en la frontera danubiana, al mando de legiones excelentes prestas a obedecer, y Cómodo mientras tanto era solo un joven sin experiencia y sin apoyos. Nada hubiese sido más fácil que eliminarlo y alzarse con el poder, para posteriormente marchar sobre Roma con el ejército. ${ }^{17}$ Después de las ejecuciones, un itálico, astuto y experto en cuestiones militares, Tigidio Perennis, se hizo con el cargo de Prefecto del Pretorio y se convirtió en nuevo

14. HERODIANO I 1-17; DióN CASIO LXXIII 10-22; EUtropio VIII 15, y AURELIO Víctor 17. Un excelente trabajo al respecto en F. Grosso, La Lotta Politica al Tempo di Commodo, Mem. Acc. Scienze Torino. Cl. Scienze Mor., Turín, 1964.

15. DIÓN CASIO LXIII 5, 1-2.

16. herodiano I 8, 7-8; véase también F. Grosso, op. Cit., 154-163.

17. Dión CASio LXXiII 5, 1-2; Pero se mantuvo fiel a la palabra dada a su amigo, y pagó el ser cumplido protector de su hijo con la muerte otorgada por este. 
hombre de confianza de Cómodo, apartando de su estima a los pocos consejeros de Marco Aurelio que aún quedaban. ${ }^{18}$ Hasta el año 185 fue el virtual dominador de la escena política romana, pero finalmente trató de suplantar al propio Cómodo y hacerse con el Imperio junto a sus hijos, pero la conspiración fue descubierta y todos murieron ejecutados. ${ }^{19}$ Fue entonces cuando el emperador decidió por primera vez duplicar el cargo del Prefecto del Pretorio para dividir su poder y tratar de restarle influencia mediante una más estrecha vigilancia $(186-189) .{ }^{20}$ De tal modo quedaron las cosas hasta la ascensión del nuevo hombre fuerte, Cleandro, un liberto frigio recientemente manumitido que había ascendido desde la posición de chambelán hasta los puestos de mayor influencia, y que ocupó el puesto entre el 189 y el $190 .{ }^{21}$ La venta masiva de cargos y el ambiente irrespirable por culpa de los delatores y espías al servicio de palacio le crearon muy pronto una gran cantidad de enemigos; además, trató de aprovecharse de su control absoluto sobre el suministro de alimentos a la ciudad para reforzar su posición y favorecer sus intereses, pero finalmente la situación se le escapó de las manos y una revuelta popular provocada por el hambre y la escasez terminó en una brutal refriega a las afueras de Roma entre el populacho y la caballería pretoriana, tras la cual Cleandro fue desprovisto de todas sus funciones por Cómodo y ejecutado en el acto. ${ }^{22}$ Su sucesor, que hallaba ante sí la tarea de enmendar y sobre todo hacer olvidar tan nefasta gestión, fue Julio Juliano, que daría paso a un personaje esencial en el reinado del presente emperador y también en los años siguientes; pieza clave en el proceso de liquidación de la dinastía Antonina, que en trece años de políticas irreflexivas y destructivas había quedado agotada y desacreditada: Leto.

Un gobierno ineficiente y cargado de lacras, unido a las continuas ofensas realizadas contra los principales pilares del estado y un desentendimiento de los problemas del Imperio llevaron a una conjura para dar muerte al emperador, movimiento que, curiosamente partió del mismo seno de los colaboradores y partícipes en el equipo de mando del propio Cómodo. ${ }^{23}$ La cabeza visible de

18. Dión CASIO (LXXIII 10,1) le acusa directamente de la ejecución de Materno y Salvio Juliano, entre otros. En ese mismo sentido se expresa al respecto HERODIANO (I 8, 2). Para la confusión entre el jurista Salvio Juliano y Didio Juliano, T. D. BARnes, «A senator from Hadrumentum and three others», Bonner Historia Augusta Colloquium 68/69, Bonn, 1970, 46; Salvio Juliano era el tío materno del que posteriormente sería emperador en el 193.

19. Cf. P. A. Brunt, «The Fall of Perennius: Dio-Xiphilinus 72.9.2», CQ 23 (1), 1973, 172-177.

20. Cf. Herodiano i 9, 10.

21. Véase Dión CASIO LXXIII 12-13; HeRODIANO I 12, 3 y 13, 1-6.

22. Existe un curioso y muy negativo juicio de AMIANO MARCELINo (XXvi 6, 8) sobre Cleandro, y también sobre otro prefecto, Plauciano, al que mencionaremos más adelante. Se destaca la rapacidad, dureza y corrupción de ambos. El fin de Plauciano está relatado en DIÓN CASIO LXXVII 3-4.

23. Marcia, amante y confidente de Cómodo, tomó parte activa en el complot, pues fue ella la que descubrió en persona que el propio emperador pensaba ya matarlos a todos; tal es la versión al menos ofrecida por HERODiAno (i 16-17), que parece siempre muy al tanto de los movimientos y entresijos palaciegos. Zósımo $(\mathrm{I} 7,1)$ acusa personalmente a Marcia de ser la mano ejecutora del emperador, aunque las otras versiones, que siguen a DIÓN CASIO (LXXIII 24), apuntan a que el veneno que ella administró fue neutralizado por una copiosa comida y tuvo que ser finalmente un atleta del gimnasio quien estrangulase al hijo de Marco. 
este complot, que no la mano ejecutora, fue el Prefecto del Pretorio, Quinto Emilio Leto, ${ }^{24}$ que ocupaba el puesto desde el 191. Las fuentes ofrecen una versión según la cual los propios cómplices en la vida desenfrenada y llena de abusos del emperador vieron como la crueldad del monarca iba a alcanzarles incluso a ellos, motivo por el cual decidieron anticiparse. ${ }^{25} \mathrm{Su}$ sucesor, elegido por los conspiradores, Helvio Pértinax, que en nada de lo planeado tenía que ver, era Prefecto también, pero a la sazón de la ciudad de Roma. ${ }^{26}$ De cualquier modo, el Imperio se encontraba en una situación insostenible; en las Galias ya se habían producido los primeros signos evidentes de un creciente descontento que muy pocos años después quedaría manifestado durante el mandato del césar Albino en esas tierras, regiones que ya no abandonarán un cierto estado de inquietud latente hasta el mismo fin del Imperio de Occidente. ${ }^{27}$ Posteriormente, nuevos síntomas de intranquilidad no fueron vistos o no quisieron ser vistos por el emperador con la atención debida, y su única respuesta fue su política constante de increpaciones y conscripciones, que fueron haciéndole aún más enemigo del senado. La conjura, pues, iba a llegar tarde o temprano, y en este caso solamente difirió su forma, indicando de paso hasta qué punto el emperador se había quedado sin apoyos, hasta en su círculo más íntimo. ${ }^{28}$ Leto y posteriormente Plauciano y Papiniano fueron las más importantes figuras en el cargo de Prefecto, en esa época de transición que iba a devengar en la llegada de los Severos. ${ }^{29}$

24. Se puede apreciar como este personaje ocupa un lugar fundamental en la primera parte de la obra histórica de Herodiano (I 16, 5; I 17, 4; I 17, 7-11; II 1, 3; II 2, 1; II 2, 5). Originario de la nobleza africana, fue el encargado de elegir a Pértinax una vez asesinado Cómodo, y también apaciguó a los soldados de la capital con un inspirado discurso para que aceptasen a su candidato, cosa que logró, al menos por un tiempo. De todos modos, parece que su actitud incompetente y su necedad lograron aumentar el malestar de los pretorianos hasta que finalmente éstos terminaron sublevándose y matando a Pértinax, -emperador con el que finalmente acabó enemistado- para poco después ofrecer el poder a Didio Juliano. Se vio libre de amenazas y tribulaciones una vez terminada la guerra civil (194-197), pues fue respetado por Severo. No obstante, no tendría tanta suerte bajo el reinado del siguiente emperador, y sería asesinado por Caracalla en el 212.

25. Véase dión CASIO LXXIII 22-24; Herodiano i 16-17, y A. Birley, «The Coups d'Etat of year 192». BJ 169, 1969, 247-280.

26. Cf. Aurelio víctor 18, 10. No obstante, algunas fuentes acusan a Pértinax de estar al tanto de la conjura, y lo señalan como sospechoso o directamente culpable en el asesinato del emperador. Cf. JuLIANO, Los Césares 312c, historia augusta, Pértinax 4, 4.

27. Cf. Herodiano in 5, 2. Para la Galia, que sufrió importantes usurpaciones llenas de repercusión y muy importantes en todo el ámbito romano tanto en el siglo iII como en el iv y el v, véase J. J. HaTT, Histoire de la Gaul Romaine, 120 a. C. - 451 d. C., París, 1966; L. Herat, Gaule Romaine, París, 1986; F. DE Coulanges, Gaule Romaine, París, 1994.

28. HERODIANO I 17, 2-11; DIÓN CASIO LXXIII 22.

29. Para la denominada "Conspiración de Plauciano», un individuo tan influyente y poderoso que al parecer quiso sustituir al final de su vida la dinastía de Severo por la suya propia, véase HERODIANO III 11-12 y la n. 37. Para Papiniano, Aurelio víctor 20, 33-34; zósimo i 9, 1 y la n. 40. 


\section{Macrino y el asesinato de Caracalla en Carras}

Tras la muerte en la ciudad de York del augusto Septimio Severo en el 211, sus hijos Geta y Caracalla habían heredado conjuntamente la dirección del Imperio, pero tras el traslado solemne a Roma de los restos del viejo emperador, la ilusión de concordia fraternal terminó y una serie de enfrentamientos enconados finalizó con el trágico asesinato de Geta en el 212, al que siguió una sangrienta represalia contra sus partidarios. ${ }^{30}$ Como parte de ella, los dos Prefectos del Pretorio, Patruino y el excelente Papiniano, fueron depuestos y/o asesinados por no querer inmiscuirse ni tomar parte en los terribles sucesos, pues quizá se les pidió una declaración justificando el parricidio. ${ }^{31}$ Acto seguido comenzó el gobierno en solitario de Caracalla, famoso por la construcción de unas grandes termas en Roma y la famosa Constitutio que otorgaba la ciudadanía romana a todos los habitantes del Imperio. ${ }^{32}$ Pero parece que la tensión no diminuyó y las fuentes literarias de carácter senatorial achacan numerosas conscripciones y represiones violentas a este emperador, que queda fuertemente denostado por su crueldad y una estrafalaria adoración de Aquiles y Alejandro Magno, aspecto por otra parte nada nuevo en la imagen de los emperadores romanos. ${ }^{33}$ Sin llegar

30. HERODIANO III 13 - IV 4; DIÓN CASIO LXXVI 7 - LXXVII 2.

31. DIÓN CASIO LXXVIII 1, 1 deja claro en cambio que antes del asesinato de Geta, Papiniano había sido destituido de su puesto y por tanto teóricamente no había motivos para mezclarlo en el asunto; véase para ello R. Syme, «Three Jurists», Bonner-Historia-Augusta-Colloquium 68/69, Bonn, 1970, 309-327, que defenderá que Papiniano ya no ostentaba el cargo de Prefecto del Pretorio al acontecer la muerte de Geta (212). El error puede venir de la Historia Augusta (Antonino Caracalla 8, 7), donde este personaje aparece todavía como Prefecto tras el asesinato de Geta. Ambas fuentes dejarán constancia de la macabra frase supuestamente pronunciada por Caracalla frente a sus soldados tras la muerte de Papiniano (DIÓN CASIO LXXVIII 4, 1; historia Augusta, Antonino Caracalla 4, 1). Por otra parte, sabemos que Septimio Severo revocó la medida anterior de Cómodo, reduciendo la Prefectura del Pretorio dual, que pasó a ser unipersonal en 193 (Cf. A. E. R. BoAK, A history of Rome to A. D. 565, New York, 1965, 254). Con la crispación producida por la intentona imperial de Plauciano y la preparación para la subida al poder de sus dos hijos, al parecer existieron de nuevo dos Prefectos (como así aparece en Herodiano III 13, 1); ya en el 198 Caracalla fue nombrado augusto, y Geta recibió el título de césar, no obteniendo el de augusto hasta el 209. Caracalla era césar desde el 193.

32. Sobre este tema se pueden consultar los trabajos de C. SASSE, Die Constitutio Antoniniana, Wiesbaden, 1958; H. Wolff, Die Constitutio Antoniniana und Papyrus Gissensis 40, Köln, 1976; M J. Bravo Bosch, La Constitutio Antoniniana, Santiago de Compostela, 1999.

33. Es muy conocida la gran admiración que existió desde siempre en Roma por este personaje, y cómo muchos de los hombres del poder desearon compararse o igualarse con él; así, Pompeyo tomó el cognomen «Magno» en honor a Alejandro, con el que se dice, tenía un moderado parecido físico en su juventud (Cf. Plutarco, Vida de Pompeyo 2). Obviamente, tras regresar victorioso de Oriente y someter al rey Mitrídates VIÉupator, Pompeyo explotó al máximo esta asociación con el macedonio, otro gran general joven y triunfante. Tras el fin de las guerras civiles, la dinastía Julio-Claudia continuó la costumbre pompeyana; Augusto, Calígula y Nerón se identificaron en algún grado con el ya mítico rey. También se equiparó a Alejandro con el renombrado príncipe hispano Trajano (Cf. A. Guzmán Guerra, F. J. Gómez Espelosín, Alejandro Magno, Madrid, 2005, 192-193). Estas comparaciones llegaron a su punto álgido con la dinastía de los Severos, y muy especialmente con el emperador Caracalla, que afirmaba que el rey Alejandro había revivido en él, por lo que plagó el Imperio de estatuas y templos donde se prodigó un nuevo culto al conquistador al que imitó en todo, incluso formando nuevas unidades militares denominadas «falanges» anacrónicamente, al estilo macedonio. Cf. Dión CAsio lxxvin 7-8; 22, 1; Lxxix 19, 2. Herodiano iv 8, 1-9; 9, 3-4. Véase también J. VoGT, «Zu Pausanias und Caracalla», Historia 18, 1969, 299-308; U. EspinosA Ruiz, Los Severos, Madrid, 1991; J. Mª. Blázquez, Alejandro Magno modelo de Alejandro Severo, en Los pueblos de España y el mediterráneo en la Antigüedad. Estudios de arqueología, historia y arte, Madrid, 2002, 319-330. 
a poder deducir el verdadero grado de oposición y hostilidad a Caracalla, sí parecen ciertas las informaciones que relacionan sus viajes por las provincias y el abandono de Roma al clima contrario a su persona que reinaba en la capital. ${ }^{34}$ En cualquier caso, el emperador se dedicó a visitar sus dominios y realizó algunas victoriosas campañas militares fronterizas, donde los alamanes, pueblo que adquiriría extraordinaria importancia en el siglo IV, aparecieron por primera vez. ${ }^{35}$ Siguiendo hacia el Este la dirección de las fronteras romanas, Caracalla acaba visitando Grecia, Mesopotamia, Siria y Egipto, donde su actitud violenta y represiva, al parecer, volvió a manifestarse. ${ }^{36}$ Por último, sabemos que estalló una guerra contra los partos, en la frontera oriental, y que el emperador en persona se hallaba allí para dirigirla con su principal ejército. Algunas fuentes señalan la actitud demencial del emperador y la traición más descarada como causantes de una guerra completamente injustificada e innecesaria, pero debe examinarse cuidadosamente el marco histórico de la misma y ponerse en antecedentes es vital para discernir la verdadera situación del momento; muy poco tiempo antes, Severo, padre de Caracalla, había librado una guerra contra los partos y llegado hasta la capital, Ctesifonte, en el 197, por lo que las bases de esta nueva guerra podrían estar relacionadas con la anterior campaña, victoriosa para Roma, con la rectificación de los límites o simplemente una secuela de índole fronteriza. ${ }^{37}$ En cualquier caso, el hecho pudo haber sido utilizado por las fuentes hostiles al emperador para mostrar una vez más su inadecuado comportamiento como emperador romano y los grandes errores de su reinado. Sin entrar a discernir la culpabilidad de dicha contienda, señalaremos solamente que en ella se hallaban también los Prefectos del Pretorio de Caracalla, M. Oclatinio Advento y Marco Opilio Macrino. ${ }^{38}$ Como consejero dentro de la cúpula militar y posiblemente administrador civil durante la campaña, su proximidad cotidiana con el emperador era más que evidente, y en el 217 Macrino decidió crear un plan para asesinar al emperador, que resultó exitoso. ${ }^{39}$ Recordemos que el propio Caracalla había mandado asesinar a otro Prefecto del Pretorio, paisano de su padre e íntimo colaborador de Severo durante muchos años, C. Fulvio Plauciano (entre el 197 y el 205), un hombre de reputación terrible en las fuentes, que supuestamente trató de eliminar al emperador y sus hijos para hacerse con el poder imperial,

\footnotetext{
34. HERODiano IV $7,1$.

35. Cf. J. F. Drinkwater, The Alamanni and Rome 213-496 (Caracalla to Clovis), Oxford, 2007.

36. Para la importante y tumultuosa ciudad de Alejandría, véase R. S. BAgnall, Egypt in Late Antiquity, Princeton, 1996.

37. Cf. N. C. Deveboise, A political history of Parthia, New York, 1968; G. Rawlinson, The Seven great monarchies of the Ancient Eastern world: or, the history, geography, and antiquities of Chaldea, Assyria, Babylon, Media, Persia, Parthia, and Sassanian or New Persian Empire, Piscataway, 2002.

38. herodiano iv 12, 1. Marco Opelio Macrino, nacido en 166; Caracalla le nombró Prefecto del Pretorio en el 213. El otro fue Marco Oclatinio Advento, hombre de extracto humilde pero con una gran experiencia militar y que llegará a cónsul en el 218. Tras proclamarse emperador, Macrino lo envió a Roma como Prefecto de la Ciudad para tratar de consolidar su poder en Occidente, pero parece que su gestión fue un fracaso, pues Advento fue pronto reemplazado.

39. HERODIANO IV 12-14.
} 
siendo descubierto y ejecutado. ${ }^{40}$ De cualquier modo, una vieja profecía asociada a su muerte por la Historia Augusta proclamaba que el siguiente Prefecto del Pretorio vengaría su muerte, como así fue. ${ }^{41}$ Pero no fue el único prefecto asesinado por Caracalla; aparte del caso anterior, que se trataba de un alto cargo que solo había servido a su padre, en el 212, una vez muerto Severo y su hermano Geta recién asesinado, procedió a librarse de sus dos propios prefectos, como hemos visto.

Acto seguido, se firmó una rápida paz con los partos, que también podría proporcionarnos algunos indicios acerca de la culpabilidad o los motivos del inicio de las hostilidades, y el nuevo emperador procedió a dirigirse hacia el interior, a Antioquía en Siria, donde poco después asociaba a su hijo Diadumeno al poder imperial con el propósito evidente de formar su propia dinastía, pero no mucho después, los soldados eligieron a Heliogábalo como monarca, y su grado de parentesco (aún dudoso) con Caracalla y los Severos selló el destino de Macrino y su hijo, que fueron asesinados en el $218 .{ }^{42}$ Cabe destacar que, pese a su propia valiosa experiencia al respecto, las fuentes acusan a Macrino de elegir dos Prefectos del Pretorio completamente vulgares y sin experiencia, como Juliano Néstor (no así Ulpio Juliano). ${ }^{43}$ La tendencia negativa continuó y se acrecentó posteriormente: Heliogábalo eligió personajes de extracción ínfima y nulas cualidades para los puestos burocráticos, administrativos y militares más altos: de entre toda la hez de actores, mimos y similares fue elegido el nuevo Prefecto del Pretorio, que a la sazón ostentaba su cargo en el año 221, P. Valerio Comazón. ${ }^{44}$ El odio y el deseo devenganza contra tales personajes, representantes de un gobierno corrupto e ineficaz, quedaron completamente descubiertos con la revuelta que condujo al asesinato del emperador Heliogábalo y su madre, tras lo cual sus cadáveres fueron vejados contundentemente por toda la ciudad; los Prefectos del Pretorio no escaparon a la ira popular y murieron asesinados también, por los mismos motivos por los que se liquidó al emperador. ${ }^{45}$

40. Cf. Dión CASio LXXIII 3, habla de que solo existían algunas sospechas hacia esta persona, hombre de confianza de Severo y quizá pariente lejano. Afirma que toda la conspiración fue un montaje de Caracalla; no así HeROdiAno (III 11-12). Véase la n. 29.

41. Cf. Historia augusta, Antonino Caracalla 8, 8-9; es curioso que por su parte ni eutropio (VIII 21) ni AURELIo víctor $(21,5)$ relacionan a Macrino con la muerte del emperador, aunque el último menciona su cargo y rango de Prefecto del Pretorio. Exactamente igual es el caso de zósimo (I 10, 1).

42. Véase H. B. Wiggers, Caracalla, Geta, Plautilla, Macrinus bis Balbinus, Berlín, 1971.

43. DIÓN CASIO (LXXIX 15, 1) los acusa igualmente de participar en todas las bribonadas y bellaquerías del difunto emperador Caracalla. Ulpio Juliano recibió el encargo de Macrino de marchar a Emesa con ciertas legiones para terminar con la sublevación de las tropas que apoyaban a Heliogábalo, pero los soldados lo abandonaron en mitad del enfrentamiento y tuvo que huir (DIón CASIO LXXIX 32, 3 y 4), para esconderse; posteriormente los pretorianos adictos a Heliogábalo lo descubrieron y procedieron a darle muerte; su cabeza fue enviada de vuelta a Antioquía, donde Macrino esperaba noticias (todo el episodio está relatado sucintamente en HERODIANO V 4, 3-4).

44. HeRODiAno V 7, 6. De cualquier modo, existe la posibilidad de que el propio Heliogábalo hubiese sido el emperador que llamase al jurista Ulpiano a la corte, un personaje de gran importancia para la historia del derecho romano y al parecer muy influyente bajo el reinado de Alejandro Severo (222-235). Pero también es posible que Ulpiano trabajase en la burocracia imperial desde tiempos de Caracalla o aun de Septimio Severo. Cf. R. Syme, art. Cit., 320 ss.

45. Cf. Dión CASIO LXXIX 21, 1. 


\section{Gordiano III y Filipo el Árabe: LA MUERTE del emperador en CirCESIUM}

Resulta significativo comprobar como tanto en el caso anterior, como en el presente, y también en el que veremos a continuación, los Prefectos del Pretorio urdieron tramas y asesinaron a sus emperadores cuando los ejércitos romanos regresaban de guerras en Persia, y además algunas veces victoriosamente. ${ }^{46}$ En unos momentos en los que se podría esperar que el emperador estuviese lo más protegido posible, acompañado por sus escoltas, estado mayor, generales y ayudas de cámara, por no mencionar un gran número de legiones y numerosos contingentes de caballería, lejos de intrigas palaciegas o maquinaciones de eunucos y cortesanos, resulta que tres emperadores fueron asesinados estando entre su ejército. Veamos el primero de esos casos.

Gordiano III, que se hallaba en Roma, había tenido noticias de una invasión de sus dominios orientales por parte de la nueva y agresiva dinastía Sasánida, que había sustituido a los partos, enemigos en Oriente de las guerras de Severo y Caracalla. ${ }^{47}$ Más organizados y fuertes, sus ejércitos se habían adentrado en Siria y Mesopotamia, por lo que envió una gran fuerza al mando de su Prefecto del Pretorio y suegro, Timesiteo, para hacer frente al problema; el propio emperador se sumaría algo más tarde a esa campaña, para estar con sus tropas y dirigirlas en el combate. En ese momento, parece que el otro Prefecto del Pretorio, Filipo, estaba relegado a un segundo lugar y era Timesiteo quien dirigía las operaciones, favorablemente para Roma y con una gran victoria en batalla campal. ${ }^{48}$ Pero

46. Es notorio el caso de Caro y Numeriano; cuando el ejército romano oriental regresaba victorioso tras destruir el poderío persa y saquear su capital, ambos emperadores perecieron en muy extrañas circunstancias, uno de ellos asesinado por el Prefecto del Pretorio Apro. Cf. Aurelio víctor 38, 4; eUtropio IX 18, 1; zonaras XII 30, 10-14; Festo Breviario 24, y también la nn. 54-57.

47. Para este tema, véase R. N. FrYe, The History of ancient Iran, Munich, 1984; J. WiesenhöfER, Ancient Persia: from 550 BC to 650 AD, Londres, 2006.

48. Este personaje, cuyo nombre completo era Cayo Furio Sabino Aquila Timesiteo, fue un excepcional servidor del Imperio, uno de los más eficaces que conocemos en el siglo iII; organizador meticuloso, buen militar, previsor y disciplinado en todos los aspectos de su prefectura, despertaba no obstante el amor de sus hombres, seguramente por la honradez, sencillez y profesionalidad con la que desempeñaba su cargo. Había ejercido muy exitosamente el complicado cargo de procurator en cuatro provincias tan diferentes entre sí como Asia, Arabia, Galia y Germania; se sabe que pertenecía a la mitad oriental del Imperio, siendo seguramente un griego de Siria, o quizás de Grecia o Asia Menor; se ha conjeturado también su ascendencia árabe, como la del propio emperador Filipo. Su pérdida fue letal y decisiva para el posterior devenir del joven Gordiano III. El emperador se había casado con la hija de su mentor, Furia Sabina Tranquilina, poco antes de partir hacia la guerra. Cf. Eutropio IX 2, 2-3, y AURELIO víctor 27, 1 donde se manifiesta que el propio Gordiano había sido con anterioridad Prefecto del Pretorio; eso es un evidente error: en la HISTORIA Augusta, Los Tres Gordianos 2, 2; 4, 2 y 30, 1 se menciona a un Mecio Gordiano, Prefecto del Pretorio en 244. La confusión de Víctor por lo tanto tuvo que aparecer forzosamente en la fuente perdida utilizada por ambos. Cf. R. Syme, art. Cit., 310. Timesiteo aparece en zósimo (I 18, 2) con el nombre de Timesicles. Para Timesiteo, véase también F. KolB, Untersuchungen zur Historia Augusta, Bonn, 1987, 52-133; J. F. Drinkwater, The Gallic Empire. Separatism and Continuity in the North-Western Provinces of the Roman Empire A. D. 260-274, Stuttgart, 1987, 246 (que nos lo muestra «degradado» (?) en Lión como procurador imperial, que no era otra que su función habitual, antes de 241); para las campañas militares contra Persia, E. Kettenhofen, «The Persian Campaign of Gordian III and the Inscription of Sahpuhr at the Ka'be-ye Zartost», in S. Mitchell (ed.), Armies and Frontiers in Roman and Byzantine Anatolia, Oxford, British Archaeological Reports International Series 156, 1983, 151-171; Y R. GöBL, Der triump des Sasaniden Sahpuhr über die kaiser Gordianus, Philippus und Valerianus, Viena, 1974. 
Timesiteo murió; no entraremos en detalles acerca del suceso por quedar muy alejado del tema que nos ocupa, pero señalaremos que con la dirección de Filipo la guerra tomó un cariz desfavorable y se produjeron algunas derrotas. Gordiano III, ya en campaña, quedó desde entonces privado de su principal apoyo y consejero; y parece que el Prefecto que le quedaba fue minando su posición como augusto dejándolo solo, privándole paulatinamente del poder, y finalmente, asesinándole. ${ }^{49}$ Después de firmar una paz desventajosa, regresa a Roma con su ejército, y al igual que Macrino, asociará a su hijo al poder. Estamos en el año 247, y ambas situaciones parecen idénticas. ${ }^{50}$ Pero los sueños dinásticos de Filipo resultarían igualmente de corta duración: tras una gran victoria sobre los godos en el Danubio (249), las legiones ilirias proclaman emperador a su general, Decio. Este reunirá sus tropas para marchar sobre Roma, y Filipo le saldrá al encuentro con sus propias fuerzas. La batalla se libró en las cercanías de Verona, y Decio logró un éxito completo, capturando y ejecutando además a su rival. En Roma, tras conocerse lo sucedido, el joven Filipo es apresado y asesinado. ${ }^{51}$

\section{Nuevamente en Persia: Apro y Numeriano}

Este último ejemplo nos lleva a la dinastía de los Caros, que llegó al poder en el 282 tras el asesinato del emperador Probo a manos de sus soldados. Es curioso comprobar como una vez más, al parecer, Caro era Prefecto del Pretorio de Probo, aunque en esta ocasión no se registra en las fuentes acusación alguna que lo implique en la muerte violenta del emperador. ${ }^{52}$

49. eutropio IX 2, 3; AURelio víctoR 27, 7; jorge Sincelo, Ecloga Chronographia p. 443, 3-9; historia augusta, Los Tres Gordianos 28, 1 y 6; Epitome de CAesaribus 27, 1-3. Un relato más desarrollado del complot en zósımo I 18, 3-19, 1. Los historiadores bizantinos ofrecen correctamente el rango de Filipo como Prefecto del Pretorio. Había sido promocionado y grandemente ayudado por su hermano Julio Prisco, que a la sazón era Prefecto del Pretorio también, en Oriente, elegido por el propio Gordiano III en el 242, por su experiencia en las cuestiones de Mesopotamia y en vistas a la gran campaña contra Persia que se estaba preparando. Logró convertir a Filipo en su colega en la Prefectura tras la muerte de Timesiteo, y una vez muerto Gordiano III (244), Filipo recompensó con largueza los múltiples favores de su hermano, nombrándole rector Orientis, prácticamente un emperador subordinado que regía los destinos del Este del Imperio desde su cuartel general en Antioquía (zósımo I 19, 2; I 20, 2). Parece que el usurpador Jotapiano acabó con él (AURELIO Víctor 29, 2).

50. Véase D. E. Trout, «Victoria Redux and the First Year of the Reign of Philip the Arab», Chiron 19, 1989, 221-233. Esta situación no hace otra cosa que demostrar el vacío de poder que se había creado verdaderamente en el Imperio romano tras la extinción de la dinastía de los Severos; con el Senado y los grandes terratenientes dudosos y las legiones cada vez más envalentonadas, los años 244-253 verán una inestabilidad que resultará catastrófica tanto frente al orden interno como a la situación de las fronteras. La falta de consenso entre los ejércitos estacionados en las diferentes zonas del Imperio fue una de las claves para que se diese tal situación. Cf. Aurelio víctor 24, 9-10; Herodiano II 6, 14.

51. zósımo I 22, 2. Filipo había asociado a su hijo Filipo II al poder; había sido nombrado césar en el 244 y augusto en el 247, pese a su extrema juventud. Cf. M. PEACHIN, Roman Imperial Titulature and Chronology, A. D. 235-284, Amsterdam, 1990.

52. Cf. Historia augusta, Caro, Carino y Numeriano 5, 4-6, 2. Existe una monografía sobre los Caros, la de P. Meloni, Il regno de Cari Numeriano e Carino, Cagliari, 1948. 
Originario de la Galia, ${ }^{53}$ Caro asoció a sus hijos al poder, dejando a Carino en Occidente y marchando hacia el Este con sus tropas; los problemas fronterizos allí, evidentes a lo largo de todo el siglo III, no recibirían una solución definitiva hasta años después, con la aplastante victoria de Galerio en el 297. El otro hijo de Marco Aurelio Caro, Numeriano, acompañó a su padre y le sobrevivió al mando de los ejércitos romanos en las fronteras orientales, tras la extraña y misteriosa muerte de su padre, que había dirigido una victoriosa campaña. ${ }^{54}$ Numeriano se vio entonces como Augusto único en Oriente, pero su posición iba a durar muy poco tiempo; su Prefecto del Pretorio que curiosamente también era su suegro, Apro, tramó un plan para asesinar al joven emperador (con lo que se puede ver que en este caso su carácter era muy distinto al de Timesiteo, verdadero mentor del joven Gordiano), ${ }^{55}$ y posteriormente ocultó el cadáver dentro de una de las literas del séquito imperial; ${ }^{56}$ excusaba la ausencia del emperador alegando que el fuerte viento del desierto perjudicaba al soberano, aquejado de una dolencia ocular. Pero finalmente el hedor del cadáver oculto hizo indagar a los soldados, que descubrieron lo ocurrido. ${ }^{57}$ En cualquier caso, la idea de mantener escondido de esta manera el cadáver de Numeriano, hasta llegar a Antioquía, o peor aún hasta Sirmio o la misma Roma, es absolutamente descabellada, lo que nos crea fuertes dudas acerca de las verdaderas intenciones de Apro y la exactitud del relato en sí. ${ }^{58}$ Pero parece que, posteriormente, el futuro emperador Diocleciano se presentó como «vengador» de Numeriano, ${ }^{59}$ y en medio de una asamblea militar mató a Apro con su propia arma. Eso no impidió que, proclamado emperador, marchase hacia Occidente con sus ejércitos para enfrentarse al hermano de Numeriano, Carino, y poner fin a su dominio en el Oeste tras una batalla y la defección de parte de sus tropas al propio Diocleciano. ${ }^{60} \mathrm{Al}$ contrario que con su hermano, las fuentes senatoriales

53. En concreto sus raíces apuntan a la ciudad de Narbona. Aunque una digresión necia y bastante estúpida de la Historia augusta (Caro, Carino y Numeriano 4-5), plantea la posibilidad de que fuese o quisiese ser considerado como originario de la misma Roma.

54. historia Augusta, Caro, Carino y Numeriano 12, 1-2; 13, 2.

55. Véase la n. 48.

56. epítome De CAESARIBUs 38, 4-5; orosio VII 24, 4: «Numeriano, que acompañó a su padre en la expedición, fue traidoramente asesinado a su regreso por su suegro Apro».

57. Cf. Aurelio víctor 38, 6; eutropio X 18, 2.

58. En este punto coinciden no obstante todos los testimonios de las fuentes, incluyendo también las versiones que ocasionalmente difieren ligeramente, como los cristianos zONARAS XII 30, 1 y OROSIO VII $24,4-25$.

59. Cf. Historia augusta, Caro, Carino y Numeriano 13-15, con un detallado relato de los acontecimientos acompañado por ciertos rasgos fantásticos y una divagación pseudofilosófica ciertamente fuera de lugar. Una narración más prosaica del acontecimiento en EUTROPIO IX 20, 1. Recordemos que también Septimio Severo se presentó en el 193 como «vengador de Pértinax», con lo que su candidatura al poder imperial ganó de inmediato el incondicional y decisivo apoyo de las legiones ilirias estacionadas en el limes danubiano. Cf. Herodiano II 9 ss; Orosio VII 17, 1.

60. Tal batalla se desarrolló cerca de los límites fronterizos de los dominios de Carino, en el valle del Margo (actualmente el río se llama Morava, y la localización más probable de la batalla nos remite a las cercanías de Orasjea Sredereva, en Serbia). Por la propia narración en las fuentes y el posterior desarrollo de los acontecimientos parece que se trató de un mero trámite formal, con poco derramamiento de sangre por la defección masiva de los soldados occidentales a Diocleciano. Cf. Historia Augusta, Caro, Carino y Numeriano 18, 2; Eutropio IX 20, 2; Aurelio Víctor 39 9-11. Véase la n. 63. 
señalan muy negativamente a Carino, al que acusan de una vida llena de excesos y maldades, a la vez que resaltan sus numerosos yerros políticos. Una de las acusaciones vertidas por la Historia Augusta es que mandó matar a su Prefecto del Pretorio, por lo demás desconocido. ${ }^{61}$

\section{Epílogo: los Prefectos del Pretorio con la Tetrarquía y Constantino}

A partir del 284, vemos el dominio total y absoluto de Diocleciano sobre la totalidad del Imperio romano, aunque muy pronto escogió a su camarada de armas Maximiano como colega en Occidente. Como hemos mencionado ya, este monarca, puesto a realizar su amplio y profundo programa de saneamiento del Estado romano, y consciente de las grandes dificultades que esa tarea iba a entrañar, no dudó en echar mano de todos los funcionarios competentes y eficaces para que le ayudaran en su empeño. ${ }^{62}$ Así, tras reorganizar y asimilar en sus propias nuevas unidades militares las tropas derrotadas, utilizó la gran influencia y valía del Prefecto del Pretorio de Carino, Aristóbulo, para sanear los nuevos dominios conquistados. Vemos como en este caso una figura reconocida por su valor mantiene su puesto, pese a venir sirviendo durante años en el gobierno de otro emperador derrotado y muerto ${ }^{63}$ Esta actitud, a la vez pragmática y justa, iba a mantenerse como una de las normas de comportamiento constantes de la Tetrarquía. A pesar de los antecedentes que hemos mencionado, y de los conflictos causados por prefectos ambiciosos en una época de gran inestabilidad que por entonces acababa de finalizar, no se eliminó su figura, pues hubiese creado un vacío imposible de llenar y tampoco se pensó en limitar sus atribuciones; simplemente, se pasó e elegir cuidadosamente para esos puestos a individuos de probada lealtad, eficiencia

61. Historia Augusta, Caro, Carino y Numeriano 16, 4-5. En tal caso, el sustituto del misterioso personaje sería Aristóbulo, de quien hablaremos más adelante. Parece claro que con ese asesinato flotando en el ambiente no aumentaría el amor del Prefecto hacia su señor el césar, en modo alguno, pero dadas las continuas muestras de eficiencia y fidelidad que las fuentes nos ofrecen sobre Aristóbulo, no nos atrevemos a afirmar que fuese el causante de la muerte de Carino, traicionándolo en plena batalla; véase la n. 63.

62. Una de las primeras obras de Diocleciano fue depurar responsabilidades sobre los crímenes anteriores, para que el poder imperial dejase de tener esa imagen débil e indefensa que permitía atacarlo con total impunidad, incluso por rebeldes de muy escasa jerarquía y potencial. Así, se encargó de matar en persona, en medio de una asamblea militar, al Prefecto del Pretorio Apro, que había asesinado a su vez al joven emperador Numeriano mientras se hallaba enfermo e indefenso. Cf. Orosio VII 25, 1; Historia Augusta, Caro, Carino y Numeriano 13, 2-4. Véase también R. ReEs, Diocletian and the Tetrarchy, Edimburgo, 2004 y la n. 59.

63. Cf. Aurelio Víctor 39, 14. Se ha conjeturado que precisamente Aristóbulo pudo defeccionar y abandonar a Carino con sus tropas en plena batalla del Margo, pasándose a Diocleciano y logrando de este modo una eventual victoria del Augusto de Oriente, que a su vez le recompensaría largamente por la ayuda prestada, manteniéndole en su favor y concediendo para él los más altos cargos y honores (como así fue). Pero nos parece que todo el episodio tiene extrañas reminiscencias que nos llevan sospechosamente al caso de los Tétricos y Aureliano diez años antes, por lo que nos inclinamos a descartar tales afirmaciones como una confusión entre las fuentes. De cualquier modo, este tema y el fin de la efímera dinastía está tratado en H. W. BIRD, «Diocletian and the Deaths of Carus, Carinus and Numerian», Latomus 35, 1976, $123-132$. 
y honradez, pero que iban a estar dotados de los mismos extensos poderes de siempre. Tenemos un excelente ejemplo de ello en el caso de Asclepiodoto, Prefecto del Pretorio del entonces césar de Occidente, Constancio I ${ }^{64}{ }^{6 n}$ cargado por Maximiano Hércules en el año 296 de la recuperación de Britania, dominada en su totalidad por el usurpador Alecto, el césar eligió para tal misión, que como se puede apreciar fácilmente entrañaba grandísimos riesgos y una dificultad no pequeña, a su prefecto, un maestro de la organización, para su preparación y desarrollo. Vemos como Constancio en ningún momento dudó de poner bajo su disposición una parte importante de la flota de guerra y de sus propias legiones, que un subordinado sedicioso e irresponsable podría haber utilizado en su propio beneficio de modo demoledor ${ }^{65}$ Pero muy lejos de ello, vemos como realizó un seguro desembarco en la isla, terminando magistralmente con la usurpación, derrotando, capturando y asesinando a su líder. El llamado Imperio britano había terminado.

Una operación naval realizada con la misma brillantez y pericia fue llevada a cabo por otro Prefecto del Pretorio tetrárquico, Rufio Volusiano, ${ }^{66}$ este caso en el Mediterráneo, y con la misión siempre delicadísima de recuperar el control sobre la provincia de África, fuente principal del abastecimiento de grano para Roma, que de ser cortado podía colocar a cualesquiera emperadores residentes en la ciudad en una situación tremendamente inestable, con una revuelta popular presta a estallar en cualquier momento. ${ }^{67}$ Hablamos del año

64. Prefecto del Pretorio primero de Maximiano Hércules y luego del césar Constancio I entre el 290 y el 296, recibió también el consulado del 292. Al parecer era un funcionario soberbiamente preparado sobre las cuestiones militares. Cf. A. H. M. Jones, J. R. MARTindAle, J. Morris, op.cit., 115, «Iulius Asclepiodotus 3».

65. Cf. Eutropio IX 22, 2; Aurelio Víctor 39, 42; Historia Augusta, Probo 22, 3. Existe una tradición no plenamente confirmada, según la cual Constancio habría sido él mismo Prefecto del Pretorio de Maximiano Hércules, entre el 285 y el 289; en ese caso, como militar con experiencia en dicho puesto, pudo conocer y valorar plenamente la capacidad de Asclepiodoto, a buen seguro ya su subalterno en el servicio imperial, depositando posteriormente plena confianza en él.

66. Parece que era veterano en esos tiempos, pues venía ejerciendo el cargo de corrector Italiae (con jurisdicción sobre el centro y sur de la península) desde el tiempo de los Caros (ca. 281-283 hasta 289. 291). Hombre de excelentes cualidades ya aprovechado por Diocleciano, servirá en su carrera política tanto a Majencio como a Constantino, demostrando una vez más la ecuanimidad, previsión y sapiencia de los monarcas tetrárquicos a la hora de rodearse de servidores aptos y competentes fuera de rencores o recelos partidistas. Prefecto de la Ciudad de Roma (310-311), será también cónsul (311) y Prefecto del Pretorio (309-310) con Majencio. Su anterior cargo como procónsul Africae (antes del 305-306) sin duda le devengó una extraordinariamente valiosa experiencia y útiles contactos y conocimientos para la complicada misión de recuperar África, en poder del usurpador Alejandro. Tras la muerte de Majencio Constantino lo honró, y fue nombrado nuevamente Prefecto de la Ciudad de Roma entre el 313 y el 315. Cf. A. H. M. Jones, J. R. Martindale, J. Morris, op. cit., 976-978, «C. Ceionius Rufius Volusianus 4».

67. La situación se repetirá con las rebeliones de Firmo en el 372 (AMIANO MARCELINO 29 5), y Gildón en el 398 (Cf. Claudiano, La Guerra contra Gildón), y ya en el siglo v, con la invasión por parte de los vándalos de esa provincia (429-430). La posesión de África era de vital importancia para cualquier emperador de Occidente; por eso Constancio II realizó considerables esfuerzos para poder controlarla cuando acaecieron las usurpaciones de Magnencio y Juliano. Recordemos que esas tierras también fueron motivo de disputa entre sus hermanos Constante I y Constantino II en el 340. La importancia de África, vital para alimentar a la población ociosa de Roma, no disminuyó con la llegada del siglo v, y su pérdida significó verdaderamente la ruina del Imperio romano en el Oeste. Lógicamente se convirtió en un objetivo de primer nivel para Justiniano, que la recuperó en el 534. Véase para todo ello J. M. BARTon, Africa in the Roman Empire. New York, 1972; E. L. MANTON, Roman North Africa, Londres, 1988; N. Geroudet, L'Afrique Romaine: de l'Atlantique à la Tripolitaine (69 - 439); París, 2005; C. Briand - Ponsart, L'Afrique Romaine (146 a. C. - 533 d. C), París, 2005. 
307 cuando Majencio, con ayuda de su rebelde padre se deshace de Severo II, y muy pronto podemos comprobar que dominaba Italia, pero en los años 308309 perdió el control sobre el grano africano por la usurpación de Alejandro, que cortó los envíos y dejó al hijo de Maximiano en una situación crítica, rodeado de enemigos y amenazado por el hambre. ${ }^{68}$ Volusiano fue encargado de una misión verdaderamente complicada y llena de obstáculos, pese a lo cual la realizó impecablemente al mando de una flota y ejército de invasión. ${ }^{69}$ Recordemos que dos grandes expediciones imperiales, provistas de abundantes suministros y tropas, fracasaron a la hora de realizar esta misión, en el 461 y el 468 , en dos colosales esfuerzos donde las dos mitades del Imperio aunaron sus medios con vistas a recuperar una provincia vital para sus intereses, fracasando en ambas ocasiones. ${ }^{70}$ Esto nos debe añadir más luz a la importancia y el valor que representó en su momento la operación de Volusiano para Majencio.

Más adelante, en el 312, Constantino, por entonces ya señor de todo Occidente después del sometimiento del recalcitrante Maximiano y la derrota y muerte del hijo de este, Majencio, decidió, en vistas a lo sucedido en su propio tiempo y con toda seguridad teniendo en mente también los recientes acontecimientos del pasado, reformar la estructura burocrática y militar del Imperio, primero someramente, y a partir de su victoria total, en profundidad. ${ }^{71}$ En este primer paso podemos clasificar su decisión de cercenar las atribuciones del Prefecto del Pretorio, privándole de su mando militar. ${ }^{72}$ De cualquier modo, nos inclinamos a pensar que sus esfuerzos iban dirigidos en mayor medida contra la guardia pretoriana en sí, más que contra el cargo institucional que representaba su jefe. Pero vemos como se comportará de la misma forma que Diocleciano cuando encuentre empleados eficientes y leales entre sus enemigos derrotados; este es el caso de Julio Juliano, significativo personaje de la aristocracia romana oriental, abuelo materno del que sería emperador Juliano, sobrino de Constantino. ${ }^{73}$ Una vez destruido el Imperio de Licinio, en el que Julio Juliano desempeñaba el cargo de Prefecto del Pretorio,

68. Véase la n. 13

69. Aurelio Víctor 40, 18.

70. Cf. A. González Blanco, Historia de Murcia en las épocas: Tardorromana, Bizantina y Visigoda, Murcia, 1998, 160, 166-168; P. HeAther, La Caida del Imperio Romano, Barcelona, 2006, 323-387 y 493 514.

71. Véase A. H. M. Jones, The Later...50-51, 100-103, 126, 370-372.

72. Cf. M. Clauss, Constantino el Grande y su época, Madrid, 2001, 78-81; J. S. WACHer (ed.), The Roman World, Londres, 2002, 457; H. A. Pohlsander, The Emperor Constantine, Londres, 2004, 74; H. BRANDT, Constantino, Barcelona, 2007, 81.

73. Julio Juliano fue el padre de Basilina, madre del emperador Juliano, y de Juliano, otro funcionario aristócrata, que posteriormente será nombrado conde de Oriente por su sobrino Juliano, entonces augusto único. Resulta curioso comprobar que el tío Juliano siguió el camino religioso del sobrino, y se convirtió igualmente al paganismo, un nuevo «apóstata». Julio Juliano había sido gobernador y Prefecto de Egipto sobre el 314, y posteriormente Prefecto del Pretorio con Licinio desde el 315 hasta el 324. Las palabras laudatorias de Constantino no eran en modo alguno pompa hueca, y en el 325 el emperador demostró con hechos su reconocimiento, nombrando cónsul a Julio Juliano junto con Sexto Anicio Paulino, otro aristócrata cristiano, por Occidente. Aparte de esas distinciones, realizó diversas misiones diplomáticas y palaciegas para sus tres señores, Licinio, Constantino I y el césar Crispo. Véase A. H. M. Jones, J. R. MARTINDAle, J. MorRis, op. cit., 478, «Iulius Iulianus 35». 
Constantino le rindió grandes honores, manteniéndolo en total libertad para continuar desempeñando el cargo bajo su nueva administración, y poniéndolo como ejemplo ante sus propios subordinados, como modelo al que tenían que imitar. $^{74}$ En cualquier caso, a nuestro entender tal honor y alabanza no dejó en demasiado buen lugar al que, alrededor del año 315, era el propio Prefecto del Pretorio del victorioso emperador, Petronio Aniano. ${ }^{75}$

\section{CONCLUSIÓN}

En definitiva, podemos ver como la evolución de esta importante institución romana desde finales del siglo ir hasta la Tetrarquía y Constantino, mostró una progresiva acumulación de poder y una gran importancia a todos los niveles, que terminaron haciendo del Prefecto del Pretorio algo parecido a un «segundo emperador» con atribuciones casi omnímodas; todavía a principios del siglo IV vemos como ciertos individuos especialmente escogidos y responsables utilizaron sus prerrogativas militares para servir de modo fiel e inapreciable a sus respectivos señores, los emperadores, pero tras su victoria absoluta en el Oeste (312), Constantino decidió cambiar el orden de las cosas, y sin prescindir de esta importante figura burocrática en su gobierno, limitó sus funciones al ámbito civil, restringiendo así su influencia y terminando para siempre con la peligrosidad en que se había convertido el mando de tropas en un funcionario tan importante, desde el fin de la dinastía Antonina.

74. Cf. Libanio XVIII 9.

75. Que no obstante, no se trataba de un personaje insignificante; cónsul posterior en el 314 junto a Rufio Volusiano (véase n. 66), fue Prefecto del Pretorio gozando de senioridad junto al propio Julio Juliano, entre el 315 y el 317 (cuando sus señores Licinio y Constantino reinaban de forma conjunta más o menos amistosamente). Sabemos también que desempeñó el cargo de vicario de África antes del 316. Cf. A. H. M. Jones, J. R. Martindale, J. Morris, op. cit., 68, «Petronius Annianus 2». 